\title{
É POSSÍVEL UMA PEDAGOGIA DAS COMPETÊNCIAS CONTRA-HEGEMÔNICA? RELAÇÕES ENTRE PEDAGOGIA DAS COMPETÊNCIAS, CONSTRUTIVISMO E NEOPRAGMATISMO
}

\author{
IS A PEDAGOGY OF COUNTER-HEGEMONIC COMPETENCIES POSSIBLE? \\ THE RELATIONSHIP BETWEEN PEDAGOGY OF COMPETENCIES, \\ CONSTRUCTIVISM AND NEO-PRAGMATISM
}

Marise Nogueira Ramos 1

Resumo Resgatando a discussão sobre a origem das competências na pedagogia e sua possível ressignificação ao subordiná-la ao conceito de qualificação como relação social, questiona-se, aqui, a possibilidade de essa noção orientar a construção de uma pedagogia contra-hegemônica. Tal questionamento é realizado analisando-se possíveis relações entre a pedagogia das competências, o (neo) pragmatismo e o chamado construtivismo radical, que podem estar fundando uma epistemologia pósmoderna, coerente com algumas tendências contemporâneas da Filosofia da Educação, com implicações sobre as teorias pedagógicas. Demonstrando que essas tendências negam a objetividade do conhecimento, admitindo-se o relativismo e o subjetivismo, conclui-se que a construção de uma pedagogia contra-hegemônica deve superar os princípios que dão significado à noção de competência e resgatar o trabalho como princípio educativo sob a perspectiva histórico-crítica das relações sociais. Palavras-chave competências; qualificação; construtivismo; pragmatismo.

\begin{abstract}
Returning to the debate on the origins of competencies in pedagogy and to the possibility of giving it a new meaning by subordinating it to the concept of qualification as social relation, this paper investigates the possibility of this notion becoming the basis for the construction of a counterhegemonic pedagogy. This investigation is carried out through an analysis of the possible relations between the pedagogy of competencies, the neopragmatism and the so-called radical constructivism, all of which may be generating a post-modern epistemology, coherent with some contemporary trends in the Philosophy of Education and with implications for pedagogical theories. By demonstrating that these trends deny the objectivity of knowledge, thus admitting relativism and subjectivism, we conclude that the construction of a counter-hegemonic pedagogy must go beyond the principles that give a meaning to the notion of competency and turn to the notion of work as an educational principle under the historicalcritical perspective of social relations.
\end{abstract}

Key words competencies; qualification; constructivism; pragmatism. 


\section{Introdução}

Para compreender as mudanças atuais na forma de se pensar e de se fazer pedagogia, indicamos em alguns de nossos trabalhos (Ramos, 2001a; 2001b; 2001c; e 2001d) que o construtivismo piagetiano constituía-se no aporte psicológico do que se tem denominado de pedagogia das competências. Apropriamo-nos, naquele momento, da tese defendida por Duarte (2000), de que a epistemologia piagetiana seria perpassada por uma ambigüidade entre, por um lado, uma tendência ao cientificismo positivista e, por outro, uma tendência a um relativismo subjetivista, este último levando ao irracionalismo pós-moderno.

Autores como Doll Jr. (1997) e Von Glasefeld (1998), por exemplo, sustentam a idéia de que, para Piaget, o conhecimento seria um instrumento mental empregado no processo de adaptação do indivíduo ao meio. A interação do sujeito com o mundo material e com os outros homens permitiria a construção de representações extraídas de seu mundo experiencial, que teriam validade somente diante de circunstâncias em que se mostram viáveis para o próprio sujeito. Assim, o conhecimento ficaria limitado aos modelos viáveis de interação com o meio, sendo a sua validade julgada não pelo potencial explicativo da realidade, mas por sua viabilidade ou utilidade que, muito além de serem históricas, são tidas como contingentes. Essa concepção opõe-se à epistemologia moderna pela negação do conhecimento como representação da realidade objetiva externa ao pensamento, admitindose o relativismo. Igualmente, anula a dimensão ontológica do processo de construção do conhecimento, pelo qual as representações da realidade objetiva são trabalhadas pelo pensamento em um processo dialético de apropriação e objetivação humanas, substituindo-a pelo subjetivismo.

A partir destas hipóteses, tentaremos apresentar algumas indicações que tornam essa epistemologia pós-moderna coerente com algumas tendências contemporâneas da Filosofia da Educação, com implicações sobre as teorias pedagógicas, principalmente quanto aos conceitos de currículo e de aprendizagem. Procuraremos, a partir disto, perceber se essas tendências podem estar fundando as bases do pensamento educacional contemporâneo sobre as quais se sustenta a pedagogia das competências em formulação atual. Veremos, então, uma possível relação dessas idéias com o neopragmatismo (Ghiraldelli, 2001), e os pontos comuns com o que se tem chamado de "construtivismo radical" (Von Glasefeld, 1998).

\section{O construtivismo como limite na ressignificação da competência}

Em um de nossos artigos (Ramos, 2001d), discutimos a predominância de três tendências analíticas sobre a origem da noção de competência: aquela 
que a associa ao condutivismo típico da década de 60, pelo qual as competências se confundem com os objetivos em pedagogia; outra, que admite esta associação, em um primeiro momento, mas aponta para uma superação do condutivismo promovida, por um lado, pelo advento da psicologia cognitiva e, por outro, pelas transformações do trabalho, distinguindo-a dos objetivos2; e uma última, que identifica a noção de competência como algo efetivamente novo e apropriado às transformações sociais e econômicas de nossa época. Não obstante, ao discutirmos esta última tendência, continuamos a afirmar que a noção de competência é originária da psicologia do desenvolvimento, seja em sua vertente condutivista ou construtivista. O fenômeno que se processa atualmente, merecedor de atenção, é a apropriação socioeconômica dessa noção, conferindo à educação o papel de adequar psicologicamente os trabalhadores às relações sociais de produção contemporâneas, o que denominamos de "psicologização das questões sociais".

Por essa perspectiva, não se estaria rompendo com nenhum dos preceitos educacionais da modernidade capitalista, principalmente aqueles relacionados com o controle e a eficiência social. Variações relativas à apropriação da noção de competência não seriam essencialmente filosóficas ou políticas, mas principalmente metodológicas. Tanto que um dos princípios fundamentais da eficiência social está no fato de as competências requeridas do educando serem investigadas no processo de trabalho, mediante o uso de metodologias predominantemente condutivistas e funcionalistas e, mais recentemente, das denominadas construtivistas 3 .

Deluiz (2001) discute a possibilidade de construção de uma matriz crítico-emancipatória, cujos fundamentos teóricos estariam no pensamento crítico-dialético, pretendendo não só ressignificar a noção de competência, atribuindo-lhe um sentido que atenda aos interesses dos trabalhadores, mas também apontar princípios orientadores para a investigação dos processos de trabalho, para a organização do currículo e para uma proposta de educação básica e profissional ampliada. Considerando que um momento crucial na construção de qualquer sistema de competência 4 seja a investigação do processo de trabalho, quando se faz a opção teórico-metodológica que condiciona os momentos seguintes, a autora nos diz que

a identificação, definição e construção de competências profissionais não se pauta pelas necessidades e demandas estritas do mercado, na ótica do capital, mas leva em conta a dinâmica e as contradições do mundo do trabalho, os contextos macroeconômicos e políticos, as transformações técnicas e organizacionais, os impactos socioambientais, os saberes do trabalho, os laços coletivos e de solidariedade, os valores e as lutas dos trabalhadores. Desta forma, investiga as competências no mundo do trabalho a partir dos que vivem as situações de trabalho, ou seja, dos próprios trabalhadores, identificando os seus saberes formais e informais, as suas formas de cul- 
tura e o patrimônio de recursos por eles acumulado (aprendizados multidimensionais, transferências, reutilizações) nas atividades de trabalho (Deluiz, 2001, p. 22).

Também sinalizamos que o movimento educacional contra-hegemônico, compreendido como aquele que se constrói em favor dos interesses dos trabalhadores e não do capital, exigiria a ressignificação da noção de competência, associada à sua subordinação ao conceito de qualificação como relação social5. Não obstante, chamamos a atenção para o fato de que a questão social não se reduz aos conceitos. Esses são mediações que permitem diferenciar as ideologias orgânicas das ideologias arbitrárias 6 e, por isso mesmo, seus significados devem ser precisos, ao mesmo tempo que devem ser enfrentados no plano concreto das relações sociais de produção, pelos sujeitos sociais organizados, como problema material sócio-histórico e ético-político.

Foi com esta convicção que procuramos, em convergência com Deluiz, traçar o que temos chamado de uma perspectiva totalizante para a noção de competência, convertendo-a em potencialidade humana de emancipação sociocoletiva e de transformação social. Consideramos então que, do ponto de vista curricular, devem-se considerar alguns pressupostos epistemológicos e ético-políticos7: a) que a realidade concreta é uma totalidade, de modo que o currículo busque abranger todas as dimensões do conhecimento, em que se incluem determinações e potencialidades técnico-operacionais, econômicas, físico e socioambientais, sócio-históricas e culturais; b) que o homem, como sujeito histórico-social, não se dispõe psicologicamente a adaptar-se às instabilidades sociais, mas a enfrentar a realidade concreta, apropriando-se dela, transformando-a e transformando-se permanentemente; c) que o processo de subjetivação não é intrínseco ao próprio indivíduo, mas síntese das relações sociais em que o homem se apropria da realidade objetiva e, assim como apreende subjetivamente suas leis, objetiva-se como ser social por meio das próprias ações sobre a realidade; d) que a contextualização dos conteúdos de ensino como mecanismo que potencializa a aprendizagem significativa não pode limitar os conteúdos à forma como se manifestam no cotidiano, mas deve levar à compreensão da realidade de forma pensada, para além do senso comum; e) que as disciplinas científicas e escolares têm uma história e uma identidade epistemológica, de modo que suas fronteiras não se dissolvem por simples opção metodológica. Portanto, a construção do conhecimento pela apropriação subjetiva dos conteúdos disciplinares processa-se como representação de uma realidade externa ao pensamento, ainda que trabalhada por ele, num processo dialético de apropriação e objetivação.

A partir destes pressupostos, tentamos propor alguns princípios teóricometodológicos que pudessem estruturar uma pedagogia das competências contra-hegemônica. Inicialmente, tomamos a noção de competência sob a ótica sócio-profissional, pela qual a competência, antes de ser um conjunto de co- 
nhecimentos, é uma atitude social. Em seguida, passamos a vê-la por uma ótica epistemológica, considerando que o desenvolvimento de competências implica a apropriação do conhecimento, mediante a articulação do pensamento com saberes formais e práticos, que estruturam fenômenos e ações, em um processo mediado por relações sociais. A aprendizagem, assim, apresentaria duas dimensões: uma subjetiva e outra objetiva, conformando uma totalidade.

Pela dimensão subjetiva, o desenvolvimento de competências seria o próprio processo de mobilização e articulação dos conhecimentos, das habilidades e dos valores no enfrentamento de situações concretas. Esse é um processo singular em que o pensamento recorre a aprendizagens de todas as ordens (formais, experienciais), que se associam às características sócio-biopsicológicas, voltadas para a ação material ou simbólica.

A dimensão objetiva da aprendizagem, por sua vez, refere-se ao conjunto de conhecimentos e relações que estruturam, interrogam e explicam os fenômenos. A análise do objeto a ser apreendido pode evidenciar esses conhecimentos e essas relações. Sob a perspectiva totalizante, portanto, qualquer objeto é parte de um fenômeno mais amplo, de modo que a apreensão de partes não determina a apreensão do todo. São as mediações constituintes do fenômeno que nos permitem compreender o objeto em sua especificidade e em sua relação com a totalidade.

Os objetos a apreender relacionam-se às finalidades educacionais ${ }^{8}$. No caso da educação básica, essas finalidades referem-se ao desenvolvimento do educando como pessoa humana, assegurando-lhe a formação necessária para o exercício da cidadania e fornecendo-lhe meios para progredir no trabalho e em estudos posteriores. A educação profissional, por sua vez, tem por finalidade o desenvolvimento de aptidões para a vida produtiva.

Nos estudos visando à formulação de propostas teórico-metodológicas que possibilitem ressignificar a noção de competência em uma perspectiva totalizante, temo-nos detido, mais especialmente, na educação profissional. Neste caso, então, o objeto a ser apreendido constitui-se no processo de trabalho para o qual o educando deverá ser preparado. Pela lógica hegemônica, essas competências são deduzidas da análise ocupacional ou funcional do processo de trabalho. Em uma tentativa contra-hegemônica, propusemos a perspectiva totalizante, pela qual se consideram o processo e as relações de trabalho como realidades históricas, contraditórias e em constante transformação. Assim, não se podem tomar exclusivamente os determinantes técnicos, operacionais e organizacionais do processo de trabalho, mas devem-se considerar as mediações de ordem econômico-produtiva, físico-ambiental, sócio-histórica, cultural e política. Deve-se considerar, ainda, que os trabalhadores compõem essa realidade objetiva, construindo relações complexas e contraditórias de trabalho.

Apontamos que a compreensão totalizante do processo de trabalho, para fins curriculares, poderia permitir relacionar os saberes científicos, técnicos, 
operacionais, organizacionais e políticos que estruturam as atividades e as relações de trabalho, aos demais saberes normalmente associados à educação básica, como os das Ciências da Natureza, das Ciências Humanas e Sociais, da Matemática e das Linguagens. Tentaríamos, assim, realizar uma formação unitária, sintetizando formação geral e profissional, conhecimento científico e técnico, trabalho e cultura.

Se compreendemos a pedagogia como a atividade social que engloba o currículo formal (saberes selecionados e organizados), o processo de ensinoaprendizagem e a avaliação por métodos apropriados, estamos afirmando que, no limite, seria possível uma pedagogia das competências contra-hegemônica, mediante um referencial teórico-metodológico centrado na práxis humana, mediada pelo trabalho, inicialmente na sua dimensão especificamente econômica - que ordena as finalidades da educação profissional - mas processualmente na sua dimensão ontológica, por tentar potencializar ações emancipatórias pelos trabalhadores.

A análise do processo de trabalho permite-nos identificar os conhecimentos que o estruturam. Sob a lógica hegemônica da pedagogia das competências, esses conhecimentos tendem a se limitar ao recorte estritamente instrumental, desagregando a formação pelo atrelamento a tarefas e desempenhos específicos, prescritos e observáveis. No sentido contra-hegemônico, esses conhecimentos seriam localizados nos respectivos campos originais da ciência e das disciplinas escolares, identificando suas relações com conhecimentos originários do mesmo campo e de campos distintos do saber científico/escolar, com o objetivo de garantir aos trabalhadores o acesso aos conhecimentos universais historicamente construídos pela humanidade. Isto, muito além de possibilitar a realização de ações técnicas, possibilitaria ações políticas e a construção de novos conhecimentos.

Quanto ao segundo pilar da pedagogia - o processo de ensino-aprendizagem - já sinalizamos que a pedagogia das competências em sua versão contemporânea aporta-se predominantemente no construtivismo piagetiano ${ }^{9}$, particularmente na teoria da equilibração ${ }^{10}$. Segundo esta teoria, ocorre um desequilíbrio estruturalmente perturbador quando o sujeito se defronta com situações desconhecidas ou desafiadoras, diante das quais ele reorganiza seu pensamento em um nível mais elevado do que o previamente atingido, em um processo recursivo que conduz a um crescimento indefinido dos conhecimentos, quer no plano quantitativo, quer no plano qualitativo. As competências seriam as estruturas ou os esquemas mentais responsáveis pela interação dinâmica entre os saberes prévios do indivíduo - construídos mediante as experiências - e os saberes formalizados.

Neste ponto, vamos perceber que Piaget compreende a aprendizagem como processo de adaptação à realidade, promovida pela coordenação das ações com os objetos e pela construção das estruturas mentais como assimilação e 
acomodação dessas ações (Duarte, 2000); estruturas mentais essas que seriam as próprias competências. A adaptação é uma categoria própria da concepção naturalista de homem, como pressuposto biológico que explicaria os processos de socialização. De acordo com essa concepção, a socialização do indivíduo é um processo de interação, de adaptação, de busca de equilíbrio com o meio físico e social. Desta forma, o desenvolvimento psicológico dos indivíduos equivaleria ao desenvolvimento de mecanismos adaptativos do comportamento humano ao meio material e social - as competências cognitivas, sócio-afetivas e psicomotoras - por meio das quais os indivíduos constroem seu conhecimento.

Sendo assim, como diria Coll (1994, apud Duarte, 2000), a finalidade da intervenção pedagógica seria contribuir para que o aluno desenvolva a capacidade de realizar aprendizagens significativas por si mesmo, numa ampla gama de situações. Este é o sentido do lema aprender a aprender, tão caro para a pedagogia das competências.

Duarte (2000) elabora uma síntese sobre os valores que sustentam esse lema, na raiz da concepção pedagógica construtivista. O primeiro é aquele que considera mais desejáveis as aprendizagens que o indivíduo realiza por si mesmo, posto que aprender sozinho seria algo que contribuiria para o aumento da autonomia, ao passo que a aprendizagem resultante de um processo de transmissão por outra pessoa poderia ser um obstáculo a essa autonomia. Isto porque a inteligência não se desenvolveria movida pela transmissão, mas sim por um processo espontâneo de auto-regulações.

O segundo refere-se à idéia de ser mais importante que o aluno desenvolva um método de aquisição, elaboração, descoberta, construção de conhecimentos, do que aprender os conhecimentos descobertos e elaborados por outras pessoas.

O terceiro posicionamento é aquele que considera que a aprendizagem significativa deve ser impulsionada e dirigida pelos interesses e necessidades do próprio estudante.

Por fim, o autor nos diz que o quarto posicionamento sustenta que o papel da educação implica preparar os indivíduos para acompanharem a sociedade em acelerado processo de mudança. Em uma sociedade em constante transformação, a transmissão de conhecimentos e tradições produzidos pelas gerações passadas perderia o sentido.

Carvalho (2001), com base em Toulmin (1971), explica que, em Piaget, a concepção de conhecimento como resultante das atividades ou das experiências de um sujeito individual que constrói interna ou privadamente seus conceitos e suas representações sobre a realidade em interação com o meio, restringe o conceito de conhecimento ao âmbito mental e de adequação das representações interiores do indivíduo às suas experiências. Piaget seria, então, herdeiro do pensamento de Kant e de Descartes. Para este último, a men- 
te do sujeito, isolada em sua individualidade, obtém um conhecimento seguro a partir da primeira certeza interna - o cogito -, gradativamente ampliada por uma cadeia dedutiva de verdades. Assim concebido, o problema do conhecimento objetivo está ligado ao da confiabilidade das representações mentais de um indivíduo, e não à criação e ao uso coletivos de conceitos e procedimentos de linguagens públicas.

A crítica que Carvalho (2001) faz a essa concepção está no fato de esta centrar-se nos aspectos internos ou psicológicos da representação mental do sujeito, desprezando o fato primordial e decisivo de que o conhecimento é necessariamente formulado em uma linguagem pública e compartilhável. Ou seja, mais do que "traduzir" representações e imagens mentais individuais, essa linguagem pública e comum é a própria condição para se desenvolver instrumentos intelectuais que tragam a possibilidade de uma significação compartilhável às experiências. Somente em relação a esses sentidos comuns e compartilháveis - cujos critérios de uso, significação e avaliação têm caráter intersubjetivo e participam de modos de vida supra-individuais - seria possível, por exemplo, falar em "verdade", "erro", "adequação" e toda uma série de outras noções relativas ao conhecimento. Sua compreensão só poderia, portanto, ser obtida tendo como referência o caráter coletivo e social desses usos e das normas que os regulam, ou seja, dos significados e da gramática dessas linguagens públicas.

O autor critica o pensamento piagetiano, com base em Putnam (1983), para o qual o conhecimento é necessariamente formulado em uma linguagem pública e compartilhável. Em outras palavras, só se poderia dizer que alguém domina um conceito quando é capaz de operar com os simbolismos de uma linguagem pública, à qual recorre para formular perguntas, estabelecer critérios de avaliação de respostas, ou mesmo identificar um problema como relevante ou significativo. Não se trata, porém, de uma linguagem que traduz um conceito mentalmente formulado, em abstração de todo o quadro de referências simbólicas compartilhadas, mas do fato de que a própria possibilidade e o significado da formulação desse conceito pressupõem toda uma iniciação no domínio específico dessa linguagem pública e nos quadros de referência que conferem operacionalidade, inteligibilidade e significação aos conceitos, procedimentos e critérios.

Sob essa perspectiva, então, o problema do conhecimento desloca o foco de atenção do âmbito mental e da adequação das representações interiores do indivíduo para o do uso comum, público e coletivo dos conceitos e procedimentos que o caracterizam como um empreendimento coletivo, social e histórico.

Von Glasersfeld (1998)11, entretanto, considera que o conceito de representação sequer sustenta a epistemologia de Piaget. Este conceito seria, na verdade, substituído pelo de adaptação, de modo que a validade do conhe- 
cimento, no mundo de nossas experiências, não seria a mesma que "verdade, no sentido ontológico ou absoluto dos filósofos" (1998, p. 20). Para ele, o conceito de adaptação, de Piaget, indica um relacionamento específico entre organismos vivos, ou espécies, e seu ambiente. Assim, dizer que eles são adaptados significa dizer que eles demonstraram ser viáveis em seu ambiente, através do conjunto da adequação de suas ações e operações conceituais com seu ambiente.

O conhecimento, então, não deveria ser tratado "como uma representação mais ou menos acurada de coisas, situações e eventos externos, mas sim como o mapeamento das ações e operações conceituais que provaram ser viáveis na experiência do sujeito conhecedor" (1998, p. 20). Desta forma, não seria possível extrair conclusões sobre o caráter do mundo real, posto que o conhecimento surgiria de ações e da reflexão das pessoas sobre suas próprias atividades perceptivas, que ocorrem em um ambiente, dirigidas a objetos que constituem seu mundo experiencial. Este ambiente e esses objetos não teriam existência independente das pessoas, tal como normalmente pensamos em nosso senso comum, ou seja, como algo previamente existente, quer nós, por acaso, estejamos nele, ou não. Em síntese, o conhecimento não existiria fora das mentes das pessoas, mas somente como ações e operações conceituais mentais que comprovam ser viáveis experiencialmente.

Assim concebendo o conhecimento, o autor considera que, no ensino e na educação construtivistas, é crucial abandonar a suposição ingênua de que o que nós mesmos percebemos e inferimos das nossas percepções está presente, pré-fabricado, para que os estudantes captem, desde que tenham vontade de fazê-lo e/ou que sejam incentivados para tal.

Concluímos então que, de acordo com essa perspectiva, o conhecimento não resultaria de um esforço de compreensão da realidade objetiva, mas das percepções e concepções subjetivas que os indivíduos extraem do mundo experiencial. A validade do conhecimento assim compreendido é julgada por sua viabilidade ou por sua utilidade exclusivamente neste âmbito e, muito além de ser considerado histórico, é tido como contingente. Ou seja, não existiria qualquer critério de objetividade, de totalidade ou de universalidade para se julgar se um conhecimento, ou um modelo representacional, é válido, viável ou útil.

Com isto, o caráter ontológico do conhecimento é substituído pelo experiencial. As categorias objetivo e subjetivo fundem-se indistintamente no processo de interação, superando proposições de certeza e de universalidade em benefício da particularidade, da indeterminação e da contingência do conhecimento. Em outras palavras, o sentido e o valor de qualquer representação do real depende do ponto a partir do qual se vê o real - relativismo - e de quem o vê - subjetivismo. Negando-se a objetividade do conhecimento e a possibilidade de explicações totalizantes da realidade, uma epistemologia 
adaptativa acaba por admitir que a realidade não é explicável, salvo por percepções particulares do sujeito cognoscente, isto é, como apreensões subjetivas. É o próprio conceito de verdade que volta a ser questionado.

Pelo que dissemos, a radicalidade do construtivismo de Von Glaserfeld está até mesmo no fato de negar o compartilhamento de uma linguagem pública como critério de verdade, tal como faz Putnam (1983, apud Carvalho, 2001). Segundo ele, haveria modos diferentes de se partilhar algo, por exemplo, em suas palavras: “se duas pessoas partilham um quarto, há um quarto e ambas vivem nele. Se eles partilham uma tigela de cerejas, nenhuma das cerejas é comida por ambas as pessoas" (Von Glaserfeld, 1998, p. 21). Em síntese, ele quer dizer que as estruturas conceituais que constituem significados ou conhecimentos não são entidades que poderiam ser usadas alternativamente por indivíduos diferentes, posto que elas seriam construtos que cada usuário teria de construir para si mesmo.

Por serem individuais, portanto, jamais se poderia dizer se uma ou duas pessoas produziram o mesmo construto. No máximo, poder-se-ia observar que, em um determinado número de situações, seus construtos funcionariam da mesma forma, provando serem compatíveis. Por isto, afirma o autor que aqueles que enfatizam a dimensão social da linguagem e do conhecimento deveriam usar a expressão de Paul Cobb (1991) "tido-como-compartilhado", que acentuaria o aspecto subjetivo da situação.

\section{Construtivismo e (neo)pragmatismo: teorias pós-modernas do conhecimento?}

Os pragmatistas clássicos definiram a experiência como uma noção capaz de superar dualidades tais como pensamento e matéria, alma e corpo, ideal e real, liberdade e necessidade, história e natureza. Pela ótica de Charles S. Peirce, um filósofo norte-americano da ciência e linguagem, o critério de verdade (não a verdade em si) deveria ser dado pelo experimento crescente e sucessivo, elaborado, acompanhado e avaliado por um grupo ideal de especialistas. Outro pragmatista clássico, William James, psicólogo e filósofo também norte-americano, considerava toda e qualquer experiência: de um homem, de um povo, de uma vida, etc., de modo que o critério de verdade teria como base a experiência em um sentido amplo, sendo a verdade aquilo que nos brinda com o consenso (Ghiraldelli JR., 2002).

John Dewey (1989) o pragmatista que mais influenciou o pensamento educacional, por sua vez, sintetizou ambas as tendências ao considerar a experiência em um sentido amplo: a experiência individual-psíquica, histórico-psíquica, comportamental; e também a experiência controlada ou semicontrolada - o experimento -, além daquela completamente livre e ao acaso 
(como as vivências). O termo "verdade" para Dewey, então, era a "assertividade garantida" - o resultado último sobre avaliações de experiências (Ghiraldelli Jr., op. cit.).

Os neopragmatistas, dos quais Richard Rorty (Ghiraldelli Jr., 2001) é o mais expressivo, valoriza, nos pragmatistas clássicos, o fato de a investigação da verdade orientar-se pela investigação de procedimentos humanos ordinários, deixando de lado a busca de uma definição final, metafísica e/ou epistemológica, a respeito da verdade. Ghiraldelli Jr. afirma que Rorty elaborou uma leitura original desses pragmatistas, transitando ao neopragmatismo, na construção de seu próprio modelo das relações "nós"-“mundo, denominado por ele "naturalista não-reducionista"12.

Rorty suprime, do modelo sujeito-objeto, a relação de representação. Segundo ele, o pragmatismo clássico já dera um passo nessa direção, ao tratar o conhecimento não como a reprodução mental de coisas exteriores, mas como "instrumentos para se lidar com a realidade", ou "determinações de como agir em resposta a certas contingências", ou, ainda, "hábitos de ação" (Rorty, apud Ghiraldelli Jr., op. cit.). Essa concepção suprimiria o problema relativo à distinção entre o fenômeno - a forma como a realidade se apresenta para nós - e a realidade concreta. Ou, em outras palavras, entre aparência e essência, deixando de ser importante construir conceitos, teorias e modelos que se aproximem o máximo possível da essência do fenômeno ou da realidade como ela é. Os conceitos seriam interessantes para lidarmos com a realidade de uma certa maneira, mas não necessariamente como mesmo sentido para todas as situações ou todos os fenômenos.

Segundo Ghiraldelli Jr. (2001, p. 88), Rorty, suprimindo a relação de representação, suprimiu também a relação de verificação, ou seja, "o evento em que algo na realidade é emparelhado com um enunciado que em princípio lhe corresponderia, autorizando-o a qualificar-se como verdadeiro - como perfeitamente correspondente ao 'algo na realidade'". Em síntese, suprimese a idéia de que os sujeitos possuam um esquema conceitual que atua sobre conteúdos empíricos vindos da experiência, a partir do qual se constróem novos conceitos; ou, em outras palavras, o princípio de distinção entre o conceito e a realidade que este conceito tenta explicar.

Ghiraldelli Jr. (2001, p. 89), explica que esta distinção é central para Rorty, constituindo-se "no processo de naturalização do quadro que explica as relações, agora, não mais entre um 'sujeito' e um 'objeto', mas decididamente, entre um 'organismo' e um 'meio'", que não podem ser postos em lugares distintos, mas sim abordados holisticamente. Disto advém o holismo ou contextualismo de Rorty, como a superação dos diversos dualismos. Em síntese, o holismo ou contextualismo constitui-se no meio natural-histórico de relações, com várias linguagens e vocabulários, sem portas ou janelas no nosso interior que dariam passagem para um mundo distinto, um mundo 
sobrenatural ou não histórico. Esse modelo denomina-se "materialista nãoreducionista"; primeiro, por mostrar de forma holística somente as relações causais; segundo, por não afirmar o real como ele é.

Se as relações organismo-meio são exclusivamente de causação por via do processo de adaptação, a investigação sobre a verdade deveria levar à investigação sobre os procedimentos humanos ordinários. Fazendo isto, a pesquisa se encaminharia necessariamente para o campo da semântica, da lógica e da filosofia da linguagem, pois investigar procedimentos humanos ordinários comuns, no caso, seria investigar procedimentos lingüísticos, comportamentos lingüísticos. Assim, o conhecimento passaria a ser considerado o conjunto de crenças cuja verdade é um qualificativo que depende de como se produzem justificações.

Essa concepção, de certa forma, já estava presente no pragmatismo clássico (e na filosofia analítica), quando se entendia que a evidência sensória fornece a evidência para a aceitação de uma teoria, para que ela seja qualificada como verdadeira. Nessa perspectiva, está também o próprio construtivismo de Piaget, no sentido de que os esquemas conceituais se consolidam pela adequação à experiência. Entretanto, por considerar a existência de esquemas conceituais prévios, o tema da verdade permaneceria, ainda, no plano da epistemologia, ao passo que os neopragmatistas colocam-na no campo da semântica e da lógica. Em outras palavras, para os neopragmatistas, a teoria da verdade seria uma teoria do significado, ou uma teoria semântica da verdade, deixando de fazer sentido uma distinção entre epistemologia - que cuida de como sabemos - e ontologia - que cuida da essência do que sabemos - que seria a dimensão não-lingüística do mundo. Nas palavras de Ghiraldelli (2001, p. 113), "torna-se desnecessário a distinção entre um esquema conceptual e um conteúdo empírico, entre declarações teóricas e declarações observacionais, entre resultados e dados, ou, enfim, entre crenças subjetivas e evidências objetivas". Esta explicação neopragmatista da verdade é uma teoria não-epistemológica.

Chegamos, então, no momento em que o construtivismo radical de Von Glaserfeld encontra-se com o neopragmatismo. Enquanto o primeiro é uma teoria que procura explicar como as pessoas conhecem, o segundo discute a possibilidade de aplicar o critério de verdade a esses conhecimento. Ambas o fazem mediante substituições de dois princípios importantes da epistemologia clássica: do modelo baseado na relação sujeito-objeto pelo modelo holístico, ou contextualista, da relação organismo-meio; da concepção do conhecimento como representação que os sujeitos desenvolvem sobre a realidade objetiva pela idéia de conhecimento como adaptação dos organismos ao meio, dada pela relação de causação.

Se o neopragmatismo considera o critério de verdade como um problema dos significados, o construtivismo radical alerta para o fato de o compar- 
tilhamento desses significados por meio de uma linguagem comum ser exclusivamente contingente, de tal modo que esses significados não podem, de forma alguma, ser considerados como uma explicação objetiva da realidade, posto ser de caráter eminentemente subjetivo. Por isso, admite-se que eles sejam, no máximo, "tidos como compartilhados" (Von Glaserfeld, 1998, p. 22). Ambas as teorias desenvolvem uma concepção naturalista de homem e subjetivo-relativista de conhecimento. Com isto, o caráter dialético do conhecimento, dado por suas dimensões ontológicas e históricas, é substituído pelo caráter experiencial. Esse modelo, chamado por alguns teóricos contemporâneos de epistemologia experiencial ou hermenêutica (Doll Jr., 1997) ou epistemologia da prática (Shön, 2000) ou, ainda, epistemologia socialmente construtivista (Von Glaserfeld, 1998), é traduzido, na verdade, pelo neopragmatismo, como a superação da epistemologia.

Esta forma de conceber o homem e o conhecimento traz implicações significativas para a discussão curricular. Doll Jr. (1997) nos trouxe essas discussões pelo que ele chamou de perspectiva pós-moderna, contrapondo-se à epistemologia moderna que, para ele, é marcada pelo positivismo e pelo empirismo, com as relações de representação e verificação sustentando a teoria do conhecimento. Segundo o autor, a separação operada pela epistemologia entre sujeito e objeto é o que teria dado sentido aos princípios lógicos de Tyler (1974) na organização dos currículos, subordinando os indivíduos aos objetivos que o encerram. Continua explicando que o fechamento deste sistema - sempre buscando fins predeterminados - o torna um sistema ideal para a mensuração, gerando um conceito de currículo medido, com cursos de estudo pré-selecionados, reforçados por planos de aulas e notas de leitura escritos de modo estanque.

Segundo o autor, nesse sistema, a pedagogia baseia-se em uma "teoria do conhecimento do espectador", levando a um conceito de instrução em que o professor (como conhecedor) mostra e transmite o a priori ao aluno. O sucesso do professor (assim como o do aluno) depende do tamanho do déficit entre a realidade ideal lá fora e a realidade existencial do aluno. $\mathrm{O}$ autor denomina este currículo de "déficit medido". O aluno é o espectador de um conhecimento a priori, um recebedor daquilo que o professor e o texto transmitem, ativo apenas no sentido limitado de cumprir a tarefa. Para ele, a "teoria do conhecimento do espectador" nos ajuda a compreender que os estudos de tempo-e-movimento de Frederick Taylor, que embasaram o planejamento curricular, incluindo os princípios lógicos de Tyler, têm origens mais profundas do que a mera eficiência científica. Eles seriam, na verdade, a expressão da epistemologia moderna - positivista e empiricista - que dominou o pensamento ocidental por milhares de anos.

Em contraste, uma epistemologia experiencial mudaria o foco de estudo para a interação entre o conhecido e o conhecedor local. O sujeito de estudo 
seria tanto o conhecedor quanto o conhecido, estabelecendo-se um discurso interativo (ou transativo), ou uma interação dialógica entre os dois. Nesse sentido, a divisão objetivo-subjetivo da filosofia moderna seria superada; o objetivo e o subjetivo se entrelaçariam um no outro, perdendo sua distintividade categórica. Doll Jr., apoiando-se no neopragmatismo de Rorty, defende a superação da tendência epistemológico-verificável pela hermenêuticohistórica, que considere o conhecimento em termos de enfrentar a realidade e não de copiá-la, e desenvolva um "vocábulo de prática", não de "teoria".

Afirma Doll Jr. que, no neopragmatismo hermeneuticamente orientado de Rorty, estariam as sementes de um novo conceito de currículo - associado não à validade dos produtos, mas à importância do processo, especialmente do processo inserido nas normas culturais, lingüísticas, interpretativas; em síntese, um conceito que opere uma mudança do ontológico para o histórico. Esta visão hermenêutica nos forneceria um conceito em que o currículo não seria apenas um veículo para transmitir conhecimento, mas um veículo para criar e recriar a nós mesmos e a nossa cultura.

Em um caminho coerente com o neopragmatismo, Doll Jr. realiza uma releituras do pensamento de Dewey (1958) resgatando a idéia do pensamento reflexivo. A reflexão seria responsável por relacionar a experiência primariamente prática com a experiência secundária da "investigacão reflexiva contínua e regulada"(Dewey, 1958, apud Doll Jr., 1997, p. 155). Em outras palavras, a reflexão relaciona pensamento teórico e prático, ou conhecimento formal e cotidiano, uma vez que toma a experiência e a examina criticamente, conectando as experiências de uns com os outros "construindo uma rede de experiências em que o passado, o presente e o futuro estão inter-relacionados. A reflexão recua e examina as experiências passadas à luz de outras associações e alternativas" (Doll Jr., op. cit., p. 157).

Tomando-se a curiosidade casual dos indivíduos como ponto de partida, e orientado pelo princípio da reflexão crítica, pública e comunal, o papel do currículo, então, não seria predeterminar experiências, e sim transformar as experiências vividas. Assim, as salas de aula seriam lugares em que as experiências "vividas" seriam abertamente analisadas e transformadas por alunos e professores explorando alternativas, conseqüências e suposições.

Ghiraldelli Jr., entretanto, compreende a teoria educacional de Dewey ainda como uma construção modernal3 cuja validade pós-moderna mantémse particularmente pelo elemento-chave que orientou toda a sua teoria educacional: a democracia nos processos educativos. Mas as suas famosas cinco etapas de pensamento e resolução de problemas ${ }^{14}$ ainda se sustentam nos princípios de representação e de verificação, posto que a aprendizagem é considerada significativa quando o estudante confirma a hipótese construída por processos experimentais, formulando uma tese, ou chega a uma conclusão através de uma heurística. Como essa aprendizagem é pragmática, a tese 
e/ou a conclusão constituem-se em representações subjetivas, cujo critério de verdade é dado por sua validade em relação ao problema investigado; qualquer nível de generalização é possível somente por se considerar a sentença explicativa (a tese e/ou a conclusão) contingentemente compartilhada na forma de uma linguagem comum. Destaque-se, ainda, que o pragmatismo como referência epistemológica para o processo de ensino-aprendizagem faz com que o mais importante seja aprender os procedimentos para se chegar à tese e/ou à conclusão do que propriamente essas últimas. Na verdade, o que importa é apreender o procedimento científico para a resolução de problemas ou, em síntese, "aprender a aprender" 15.

O currículo neopragmatista, este sim considerado por Ghiraldelli Jr. (2001, p. 157) como uma revolução pedagógica pós-moderna, tem como princípio organizador as narrativas e, como elemento-chave, a emergência da metáfora. Mas como é compreendida a metáfora? Não na sua definição tradicional, como uma mensagem a ser decodificada por investigação semântica e, portanto, portadora de um conteúdo cognitivo que poderia ser explicado. A metáfora

“não é uma mensagem, não tem um conteúdo cognitivo a ser decodificado. Ela é, sim, um ato inusitado no meio do processo comunicacional que, embora tenha efeitos de grande impacto sobre o ouvinte, não pretende lhe dizer coisa alguma. É claro que uma metáfora, depois de algum tempo, se for saboreada e não cuspida e esquecida, pode então se adaptar a um jogo de linguagem existente ou forjar um novo jogo de linguagem e, então, se literalizar, ou seja, ganhar valor de verdade. (...). Mas, em um primeiro momento, ela não é uma explicação e não tem valor de verdade na medida em que não está nos quadros do jogo semântico tradicional" (Ghiraldelli Jr, 2001, p. 166).

O currículo neopragmatista teria como princípio a auto-organização, com uma matriz não-linear e não-seqüencial, sem início nem fim, somente com fronteiras e pontos de interseção ou focos e uma rede relacionada de significados (Doll Jr., 1997). O movimento didático desse currículo constitui-se, segundo Ghiraldelli Jr, em: 1) apresentar problemas na forma de narrativas; 2) propor ao estudante que se assuma como personagem dessa narrativa; 3) propor ao estudante que redescreva as narrativas originais por meio de outras narrativas, sem hierarquia epistemológica, posto que não haveria narrativa que apreende a "realidade como ele é", mas haveria, em cada uma, jogos de linguagem distintos que estariam aptos, pragmaticamente, para situações distintas; a distinção, a validade ou a adequação dos vocabulários darse-ia pela utilização lingüística que se faria deles; 4) solicitar ao estudante suas narrativas de redescrição, discutindo sua pertinência com colegas, professores, livros e outros meios, sendo este o momento da criação, de imagina- 
ção e, portanto, o auge do processo de criação de metáforas; 5) selecionar metáforas para a condução intelectual, moral e estética no campo cultural, social e político de cada um.

\section{A Insuficiência da pedagogia das competências: compreender o conhecimento como possibilidade ontológica e construção histórica}

O que discutimos até aqui fundamenta, de forma mais aprofundada, o que já havíamos apresentado em Ramos (2001a): que a concepção naturalista de homem compreende a socialização das pessoas como um processo de interação, de adaptação, de busca de equilíbrio com o meio físico e social, de modo que fatores internos e externos ao indivíduo se inter-relacionam continuamente, formando uma complexa combinação de influências que concorrem para a formação da personalidade dos indivíduos.

Nessa perspectiva, características internas e inatas do indivíduo seriam mediadoras na relação entre o organismo vivo, a espécie a que pertence e seu meio. Nisto se resume a relação de causação entre organismo-meio, única relação admitida pelo neopragmatismo. O desenvolvimento psicológico e lingüístico dos indivíduos, assim, equivaleria ao desenvolvimento dos mecanismos adaptativos do comportamento humano ao meio material e social, ou mecanismos de causação, que seriam as próprias competências. Pela perspectiva do construtivismo e do pragmatismo clássico, essas competências seriam de ordem cognitiva; enquanto para o neopragmatismo, baseando-se numa "teoria semântica da verdade" (Ghiraldelli Jr., 2001, p. 111), esses mecanismos constituem a competência lingüística. Compreendemos, então, agora de uma forma mais aprofundada, porque percebemos as referências teóricas à noção de competência se apoiarem ora na teoria construtivista, ora na teoria lingüística16.

Também na obra citada, indicamos que a concepção naturalista de homem redunda na concepção subjetivo-relativista de conhecimento. Isto é, o conhecimento construído pelo indivíduo com base nas relações de adaptação/causação, não resultaria de um esforço de compreensão da realidade, de captação das mediações e de apropriação de seus fundamentos. Ao contrário, o conhecimento seriam percepções e concepções subjetivas que os indivíduos extraem do seu mundo experiencial. O conhecimento ficaria limitado aos modelos viáveis de interação com o meio, não tendo qualquer pretensão de ser reconhecido como representação da realidade objetiva ou como verdadeiro.

A concepção naturalista de Homem é coerente com a concepção funcionalista da sociedade, pela qual a ação dos indivíduos ocorre de acordo com as determinações naturalmente dadas, visando ao equilíbrio natural e social. 
As competências constituem os parâmetros de seleção natural e social, sob os quais se dissolvem as diferenças que definem as classes fundamentais. Uma vez que a realidade não pode ser explicada, mas somente experienciada, nega-se a possibilidade de se conhecer a essência de objetos e fenômenos do mundo exterior, posto que somente as partes visíveis dos fenômenos sua aparência - podem ser captadas/experienciadas. O que está oculto, normalmente as contradições, não pode ser captado, pois transcende o mundo experiencial.

Neste ponto, convém recolocar o desvio irreparável que faz o pensamento pós-moderno ao criticar os princípios da modernidade, o positivismo e o empirismo. Primeiro, esquece que a crítica ao positivismo e ao empirismo está na raiz do materialismo dialético e atinge também a alternativa hermenêutica. Segundo, o pensamento pós-moderno toma a crítica à razão intrumental-positivista como crítica a toda razão, ignorando que a crítica fundamental realizou-se pela razão dialética.

Marx (1991) afirma que a aparência empírica da sociedade, assim como da natureza, é superficial e contradita pelo caráter de sua realidade subjacente. As aparências reais, mas superficiais, ao serem registradas como idéias espontâneas dos indivíduos, são conceitualizadas na linguagem ordinária. A função real da teoria cientifica é penetrar a superfície empírica da realidade e captar as relações que geram as formas fenomênicas da realidade, sua aparência, ou sua forma sensível. Assim, os conceitos teóricos da ciência não são redutíveis a conceitos observáveis, como no empirismo, nem são construções subjetivas impostas à realidade pelos teóricos, como no idealismo. Os conceitos científicos procuram descrever os aspectos não observáveis da realidade, que se manifestam de forma contraditória.

Portanto, o processo de conhecimento é movido por uma dimensão ontológica, admitindo-se que a realidade existe objetivamente, isto é, independentemente das formas naturais e relativamente independente das formas sociais. Essa dimensão articula-se com a modificação prática da natureza e a constituição da vida social. Por outro lado, pelo fato de a realidade concreta manifestar-se como fenômeno, enquanto o pensamento busca captar sua essência, o conhecimento é um produto histórico construído pela práxis social, que se constitui no próprio processo de formação humana. Ou seja, o homem age sobre a realidade objetivando-se como ser genérico, o ser humano, mas também apropria-se dessa realidade. A dimensão contraditória da vida humana tecida sobre a realidade concreta - que inclui a descontinuidade, o fenômeno, o fragmentário e o efêmero, mas mantém a essência na unitária síntese do diverso - é o fundamento da razão dialética que não existe fora da realidade e tampouco concebe a realidade fora de si mesma.

A razão dialética parte dos fenômenos para a essência, das partes para o todo que as supera, concebendo a construção do conhecimento como proces- 
so histórico e dialético de questionamento permanente à realidade dada e de tentativa de compreensão totalizante dessa realidade. A síntese, para a dialética, nunca é ponto de chegada, mas sempre ponto de partida, num processo de superação de cada grau atingido pelo conhecimento humano. Por isso, “não confunde o relativo com o absoluto, mas compreende e realiza a dialética de relativo e absoluto no processo histórico" (Kosik, 1976, p. 97). A relação sujeito-objeto é, portanto, uma construção de caráter ontológico e histórico, construída e apreendida pela práxis.

Os pragmatistas e neopragmatista entenderam a relação sujeito-objeto não como síntese dialética, mas como uma dicotomia, definindo a noção de experiência para superá-la. Mesmo que essa noção se aproxime da noção marxista de práxis, como afirma Ghiraldelli Jr. (2002), “em Marx há uma férrea teleologia encravada na noção de praxis, nos pragmatistas pioneiros não há qualquer teleologia na noção de experiência". Com isto, suprime-se a característica fundamental que define o homem como ser histórico-social: a capacidade de definir e orientar as finalidades de suas ações e, portanto, de ser sujeito na produção de sua própria existência. Substitui-se o modelo sujeitoobjeto pelo de organismo-meio; a idéia de unidade e diversidade pela de holismo ou contextualismo; e a de relação dialética pela de interação dialógica. O trabalho então deixa de ser uma mediação fundamental da práxis (em suas características ontológicas e históricas), sendo substituído pela linguagem como mediação das experiências intersubjetivas.

Mas, se reafirmamos a validade filosófica e ético-política do materialismo dialético, temos de resgatar a concepção histórico-social de homem. O homem, enquanto age sobre a natureza produzindo meios adequados à satisfação de suas necessidades, objetiva-se em sua produção e se transforma também subjetivamente. A realidade objetivada pelo homem é historicamente apropriada por outros homens com o sentido de reproduzir continuamente as funções humanas. Isto constitui a práxis humana - relação entre objetivação e apropriação no processo de produção da existência humana mediada pelo trabalho - e nisto está o fundamento histórico do conhecimento, como motivação e resultado do agir humano de forma consciente e planejada (teleológica) e não somente adaptativa.

\section{Concluindo - propondo}

No primeiro item deste trabalho, defendemos uma pedagogia das competências centrada na práxis humana, compreendida como processo por meio do qual os homens produzem socialmente sua existência mediado pelo trabalho. Nessa perspectiva, o conhecimento constrói-se pela busca histórica de compreensão da realidade em sua essência, ultrapassando suas aparências feno- 
mênicas. Isso pressupõe conceber o conhecimento como possibilidade ontológica e como produção social e histórica. A educação comprometida com a possibilidade de os trabalhadores tornarem-se dirigentes deve, então, proporcionar a compreensão da realidade social e natural, com o fim de dominá-la e transformá-la. Assim, todos os indivíduos devem ter acesso a esses conhecimentos, como meio de compreensão da realidade o mais objetivamente possível em cada momento histórico. A noção de competências tem seus fundamentos filosóficos e ético-políticos radicalmente opostos a essa perspectiva.

Portanto, para ser possível uma pedagogia das competências contra-hegemônica teríamos de suprimir exatamente o termo que nos impede de admitir os princípios anteriores: competências. Voltamos, então, à questão central da formação humana sob o modo de produção capitalista: a necessidade de construção de uma pedagogia contra-hegemônica, que seja ativa e criadora, construída com base em uma profunda e orgânica ligação entre ela e o específico dinamismo social objetivo que nela se identifica. Concluímos, então, que a pedagogia contra-hegemônica pode ser construída na perspectiva históricocrítica, resgatando o trabalho como o concreto princípio educativo. 


\section{Notas}

1 Doutora em Educação pela Universidade Federal Fluminense; Vice-Diretora de Ensino da Escola Politécnica de Saúde JoaquimVenâncio, Fiocruz, e Professora da Faculdade de Educação da Universidade do Estado do Rio de Janeiro. <mramos@fiocruz.br>

2 Em tese, a noção de competências se associa à transferência e à mobilização de conhecimentos diante de situações complexas. O mesmo não ocorre com os objetivos. Porém, quando se tenta nomear, classificar, repertoriar as competências ao acrescentar ao verbo saber ou à locução ser capaz de uma expressão que caracteriza uma ação ou um conjunto de ações, o que se designa é, na verdade, uma atividade e não a competência. Os objetivos indicam o que se espera que os alunos sejam capazes de realizar ao final de um processo de formação, normalmente descrito em termos de uma atividade. A competência seria o que subjaz, o que estrutura ou o que sustenta a atividade.

3 Esta última tem sido desenvolvida por Bertrand Schwartz (apud Mertens, 1996) com organizações de trabalhadores franceses. Não discutiremos os fundamentos e os modelos dessas matrizes, não somente por não ser esta a preocupação central deste artigo, mas também porque o leitor poderá encontrar análises pormenorizadas em Mertens (1996), também exploradas por nós (2001a) e por Deluiz (2001), entre outros.

4 Definimos, como sistema de competência, o conjunto associado de quatro elementos ou etapas, cada qual com suas especificidades, mas articuladas em torno de um marco teórico-metodológico que, em certa medida, acaba sendo definido pela matriz de investigação do processo de trabalho. Os elementos de um sistema de competência são: investigação, normalização, formação e avaliação/certificação.

5 Sobre a construção sócio-histórica do conceito de qualificação, recomendamos a leitura de Ramos (2001a ou 2001b).

6 Sobre a distinção entre as ideologias orgânicas das arbitrárias, tal como utilizamos aqui, ver Gramsci (1966).

7 Esses pressupostos estão descritos em Ramos (2001a, 2001c).

8 Aqui faremos referência às finalidades descritas na Lei de Diretrizes e Bases da Educação Nacional (Brasil, 1998), abstendo-nos de análises mais aprofundadas dos sentidos históricos e filosóficos da educação que condicionam suas finalidades.

9 Em Ramos (2001a), problematizamos a abordagem construtivista de Piaget apontando seus limites. A problematização e a crítica mais completa a essa teoria encontram-se, entretanto, ao nosso ver, em Duarte (2000). Recomendamos, também, a leitura de Carvalho (2001).

10 De acordo com Piaget, o desenvolvimento cognitivo é um processo de sucessivas mudanças qualitativas e quantitativas das estruturas cognitivas derivando cada estrutura de estruturas precedentes. Ou seja, o indivíduo constrói e reconstrói continuamente as estruturas que o tornam cada vez mais apto ao equilíbrio. Essas construções seguem um padrão definido por Piaget como estágios relativos a idades mais ou menos determinadas. Pela teoria de Piaget, a construção do conhecimento ocorre quando acontecem ações físicas ou mentais sobre objetos que, provocando o desequilíbrio, resultam na construção de esquemas ou conhecimentos. Os esquemas podem ser compreendidos como estruturas que se mo- 
dificam com o desenvolvimento mental e que se tornam cada vez mais refinadas à medida que a criança torna-se mais apta a generalizar os estímulos. Por este motivo, os esquemas cognitivos do adulto são derivados dos esquemas sensório-motores da criança e os processos responsáveis por essas mudanças nas estruturas cognitivas são assimilação e acomodação (Malglaive, 1995).

11 Este autor é considerado o pai do construtivismo radical (Fosnot, 1998). Duarte (2000) constrói densamente a crítica à posição deste autor, com base no materialismo dialético, discutindo sobre a incompatibilidade dessa perspectiva e a teoria de Vygostsky, frente às tentativas de alguns leitores do psicólogo russo em compatibilizar suas idéias com as de Piaget.

$12 \mathrm{O}$ autor explica que essa transição se fez mediante a articulação das leituras que Rorty fez dos pragmatistas clássicos com elaborações de filósofos analíticos, tais como Willard V. O. Quine e Donald Davidson (Ghiraldelli Jr., 2001, p. 88).

13 Lembremos que a transição do pragmatismo para o neopragmatismo processa-se pela superação da idéia de existência prévia de um esquema conceitual e, portanto, da permanência da dicotomia entre o sujeito que conhece e o objeto a ser conhecido. Parece-nos, portanto, coerente, considerar o pensamento de Dewey ainda moderno, posto que, mesmo tentando superar esta dicotomia pela categoria da experiência, ainda há o pressuposto sobre a existência do conhecimento teórico e do conhecimento prático, que se sintetizam pela reflexão, admitindo-se, assim, o esquema conceitual prévio.

14 Doll Jr.(1997, p. 155) assim resume esses cinco passos: 1) sentir o problema, 2) definir o problema, 3) levantar hipóteses para a solução do problema, 4) raciocinar logicamente sobre o problema e métodos de solução, 5) testar a hipótese desenvolvida pela ação. Ghiraldelli Jr. (2001, p. 159) organiza esses passos em termos didáticos da seguinte forma: 1) atividade e pesquisa, 2) problemas, 3) coleta de dados; 4) hipóteses e/ou heurística; 5) experimentação e/ou julgamento.

15 É importantíssima a leitura de Duarte (2000) pela crítica que faz ao lema "aprender a aprender", largamente difundido pelas políticas educacionais atuais, numa perspectiva neoliberal e pós-moderna. O autor constata que, no Brasil, este lema, entendido como emblema dos ideais pedagógicos escolanovistas, manteve-se presente nos e forte no ideário pedagógico, inclusive pela maciça difusão da epistemologia genética de Piaget, por meio do movimento construtivista, difundindo uma série de princípios que, como já dissemos, esvaziam o papel da escola como transmissora e difusora dos saberes científicos socialmente e historicamente construídos.

16 Em Ramos (2001, p. 161), fizemos referência explícita à epistemologia genética de Jean Piaget e à teoria lingüística de Noam Chomsky. Neste momento, entretanto, consideramos que a complexidade das relações que aqui analisamos recomenda nos precavermos de referências mais específicas. 


\section{Referências}

BRASIL.1998. Lei no 9.394, de 24 de dezembro de 1996. Estabelece as Diretrizes e Bases da Educação Nacional. Educação Profissional: Legislação Básica. 2a ed. Brasília, PROEP.

CARVALHO, José S. F. 2001. Construtivismo: uma pedagogia esquecida da escola. Porto Alegre: ArtMed.

СОВB, P. 1991. Reconstructing elementary school. Focus on Learning Problems in Mathematics.

DELUIZ, Neise. 2001. O modelo das competências profissionais no mundo do trabalho e na Educação: implicações para o currículo. Boletim Técnico do SENAC. Número Especial. (março de 2001).

DEWEY, John. 1958. Experience and nature. New York: Dover Publications. 1958 1989. Cómo pensamos. Buenos Aires: Ediciones Paidós Ibérica.

DOLL Jr., William E. 1997. Currículo: uma perspectiva pós-moderna. Porto Alegre: Artes Médicas.

DUARTE, Newton. 2000. Vyigotsky e o "aprender a aprender". Crítica às apropriações neoliberais e pós-modernas da teoria vigotskiana. São Paulo: Editora Autores Associados.

FOSNOT, Catherine T. 1998. Construtivismo. Teoria, perspectivas e prática pedagógica. Porto Alegre: ArtMed.

GHIRALDELLI JR., Paulo. 2001. Neopragmatismo, escola de Frankfurt e marxismo. Rio de Janeiro: DP\&A Editora.

_.Pragmatismo. 2002. Disponível em $<$ www.filosofia.pro.br/curso > .

GRAMSCI, Antonio. 1966. Concepção Dialética da História. 9. ed. Rio de Janeiro: Civilização Brasileira.

KOSIK, Karel. 1976. Dialética do Concreto. 2. ed. Rio de Janeiro: Paz e Terra.
MALGLAIVE, Gérard. 1995. Ensinar Adultos. Porto: Porto Editora.

MARX, Karl. 1991. A Ideologia Alemã. 8. ed. São Paulo: Hucitec.

MERTENS, Leonard. 1996. Sistemas de Competencia Laboral: surgimiento y modelos. México: Cinterfor/OIT.

PUTNAM, H. 1983. Teorias da Linguagem, teorias da aprendizagem: o debate entre Piaget e Noam Chomsky. São Paulo: Cultrix/Edusp.

SCHÖN, Donald. 2000. Educando o Profissional Reflexivo. Porto Alegre: ArtMed.

RAMOS, Marise. 2001a. A Pedagogia das Competências: autonomia ou adaptação. São Paulo: Cortez. . 2001 b. Os limites da noção de competência sob a perspectiva da formação humana. Movimento, Revista da Faculdade de Educação da Universidade Federal Fluminense, 2(4):47-64. 2001c. Qualificação, certificação e competências: visão educacional. Formação, Revista do PROFAE, 1(2):17-26. . 2001d. A pedagogia das competências e a psicologização das questões sociais. Boletim Técnico do SENAC. Número Especial. (março de 2001): 26-35.

TOULMIN, S. J. 1971. La comprensión humana. El uso colectivo y la evolución de los conceptos. Madrid: Alianza.

TYLER, Ralph. 1974 Principios Básicos de Currículo e Encino. Porto Alegre: Globo.

VON GLASERFELD, Ernst. 1998. Construtivismo: aspectos introdutórios. In: FOSNOT, Catherine Twomey. Construtivismo. Teoria, perspectivas e prática pedagógica. Porto Alegre: ArtMed. 